\title{
RESENHA DE INSÓLITAS: NARRADORAS DE LO FANTÁSTICO EM LATINO-AMÉRICA Y ESPAÑA. DE TERESA LÓPEZ-PELLISA E RICARD LUIS GARZÓN (EDS.). MADRID: PÁGINAS DE ESPUMA, 2019
}

Alejandra Judith Josiowicz

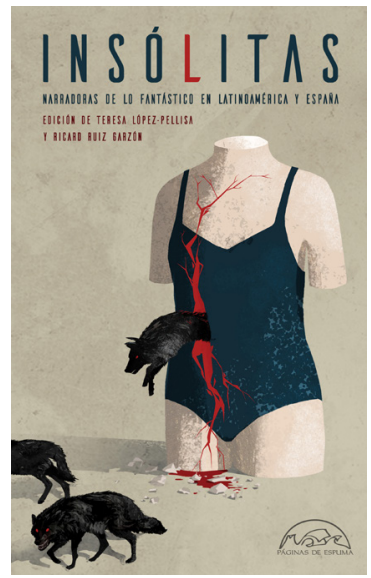

Em entrevista a Noemi Ulla, Silvina Ocampo explicava a proximidade que sentia pela estética de Clarice Lispector e afirmava:

Era uma mulher que tinha sentimentos que coincidia com os da gente, um pouco de capricho, muita graça. Eu gostava de como ela escrevia. Tinha essa coisa evanescente, que era seu encanto. Li uma entrevista na qual dizia que não Ihe interessava ter uma grande fama de escritora. Interessava-Ihe sua casa. (ULLA, 2003, p. 40-41)

1 Todas as traduções são minhas. 
Ocampo propunha construir uma aliança entre mulheres escritoras latino-americanas, unidas por questões estéticas e pela forma ambivalente como se posicionavam diante da legitimação do campo literário. Ocampo sinalizava, através dessa aliança, um desconforto com os espaços de poder hegemônicos e os cânones estabelecidos e o descentramento da aproximação à linguagem literária. Em outra parte da entrevista, Ocampo expressava incomodidade com as correções que Pedro Henríquez Ureña, intelectual e crítico literário dominicano nessa época residente na Argentina, tinha sugerido nos seus contos, apagando a oralidade, as marcas da fala e os modismos argentinos (ULLA, 2003, p. 35). Crítica dos purismos, Ocampo reivindicava um espaço cotidiano, oral, da linguagem literária, sugeria uma relação dinâmica entre escrita e oralidade e uma ideia de língua "imperfeita", "em formação" (ULLA, 2003, p. 35).

O livro Insólitas: Narradoras de lo fantástico em Latinoamérica y España se propõe responder, de forma inovadora e atual, a esses questionamentos formulados pelas escritoras centrais para a tradição literária hispânica: Como repensar o espaço da enunciação? Como tomar a palavra, como mulher, uma palavra constitutivamente alheia, marcada por hierarquias geopolíticas, linguísticas, de idade e gênero? Como 
enunciar uma palavra atravessada pela lei paterna e pela cultura masculina? Tal como lemos em Insólitas, a escritora é "literariamente filha do Pai, de sua lei, de sua cultura - o grande parto masculino contra-Natura [...]. Não há nenhum referente feminino materno: não há genealogia feminina da cultura" (LÓPEZ PELLISA; RUIZ GARZÓN, 2019, p. 4).

Insólitas está atravessado pela tentativa de fundar e refundar uma nova tradição da literatura hispânica a partir das mulheres e sua contribuição ao insólito - talvez não seja totalmente adequado falar de cânones ou tradições, porque a escolha é justamente questionar os cânones e a tradição. Nele é notável a presença, mesmo que em ocasiões implícita mas não por isso menos relevante, das fundadoras: as anglosaxãs, Margaret Cavendish, Mary Shelley, Ursula K. Le Guin; as hispânicas Sor Juana Inés de la Cruz, Eduarda Mansilla, Juana Manuela Gorriti, Emilia Pardo Bazán, Mercé Rodoreda, Ana María Matute, Rosa Montero, Alejandra Pizarnik, Elena Poniatowska, Elena Garro, Margo Glantz, e a própria Silvina Ocampo são evocadas, mencionadas, rescritas, parodiadas, repensadas sob nova luz nessas páginas. Não é casual que várias das escritoras incluídas tenham traduzido, estudado ou escrito sobre essa geração de predecessoras. Mas a complexidade e riqueza da proposta não se reduz a uma 
revisão dos cânones literários, porque não se trata de uma aposta exclusivamente acadêmica. De fato, a tradição alternativa proposta em Insólitas é passível de ser lida por um público amplo, de circular amplamente no mercado literário, como insumo para cursos de Línguas e Literaturas Hispanoamericanas, mas também chegando a públicos amplos e à comunidade em geral, o que resulta muito oportuno e diz respeito à hibridez e à riqueza do gênero e sua aceitação entre cada vez mais faixas de público.

Insólitas é uma antologia de contos de escritoras das diferentes ramas da narrativa não realista em Latinoamérica e Espanha, que inclui um prólogo no qual as editoras discutem o lugar das mulheres na cultura e na literatura e desentranham diversas perspectivas taxonômicas sobre o insólito- seja do ponto de vista acadêmico ou do setor editorial, do jornalismo e dos públicos amplos. A presença desta multiplicidade de perspectivas para pensar o insólito é sintomática e aponta para uma das chaves de compreensão do livro, que é a rejeição dos purismos, a quebra das fronteiras, a criação de pontes entre a oralidade e a escritura, o âmbito íntimo e o campo literário, o privado e o público, o masculino e o feminino, o tecnológico e o biológico, a ciência e a literatura. Insólitas questiona todo essencialismo 
e afirma: "as editoras consideramos que os binômios razão e loucura, natureza e cidade, homem e mulher respondem a categorias essencialistas geradas pelo saber humanista patriarcal androcêntrico e antropocêntrico" (LÓPEZ PELLISA; RUIZ GARZÓN, 2019, p. 8). De fato, as editoras rejeitam a categoria de "fantástico feminino", assim como a de "insólito feminino", como conceitos passiveis de gerar exclusão e discriminação e que devem ser questionados.

O livro se posiciona em um espaço híbrido, fronteiriço, e por isso extremamente relevante em um contexto de leitura e ensino digital em tempos de pandemia. De maneira absolutamente consciente, ocupa um espaço entre a academia, a indústria editorial e os públicos amplos, entre os cânones e sua renovação, entre a tradição hispano-americana e a espanhola, entre o feminismo e a desconstrução dos essencialismos ligados ao gênero. Desse modo, foge dos dualismos persistentes na tradição ocidental, sistemáticos nas lógicas e práticas de opressão das mulheres e dos constituídos como outros raciais, de classe, sexualidade e gênero. Como afirma a teórica Donna Haraway, é possível encontrar uma forma de fugir desses dualismos pelos quais temos explicado nossos corpos e nossas ferramentas, não criando uma linguagem comum, mas uma multiplicidade de 
línguas e linguagens, de formulações, categorias identitárias, relações, teorias (1991, p. 177).

Insólitas vai nessa direção, através de uma perspectiva panorâmica e não monolítica. Incorpora nomes consagrados e canônicos e outros menos conhecidos, de escritoras de 13 países, dentre os quais Espanha, Argentina, Bolívia, Peru, Colômbia, Uruguai e São Salvador. A seleção prioriza a qualidade, mas também a variedade e multiplicidade geográfica, geracional e de subgêneros ao interior do insólito, e considera o prazer e a experiência do leitor. Há, além disso, uma variedade de temáticas, dadas pelos diferentes contextos sociopolíticos e geográficos, e uma multiplicidade de procedimentos formais, de tipos e maneiras de experimentação estética. Em lugar de um tema unificante, temos diferentes temas, dentre os quais a alteridade, a diversidade sexual, a misoginia, a violência de gênero, a crítica ao cânone de beleza, os corpos não normativos, a doença, a infância, a morte, o trabalho, a monstruosidade, a ecologia, a imigração e as guerras.

Em contos como "Eu crocodilo", da salvadorenha Jacinta Escudos, aparece a metamorfose e a crítica ao patriarcado, em diálogo com as teorias de Rita Segato sobre a violação como ato ritual de poder e dominação (2013). "Sangue 
Correr", da colombiana Laura Rodríguez Leiva, explora o sangue, o monstruoso e os tabus associados ao corpo feminino. O monstruoso também aparece em "Vida de Perros", da argentina Ana Maria Shua, conto que tematiza o discurso sobre a saúde mental, a obsessão psicanalítica da sociedade argentina, e os preconceitos que surgem diante de corpos não normativos. O monstruoso ainda está presente em "O hóspede", conto da mexicana Amparo Dávila, no qual é articulado com a denúncia da violência de gênero.

"A Casa Encantada", da argentina Mariana Enríquez, reescreve a Silvina Ocampo e repensa a infância e os corpos não normativos, de modo tal que evita a vitimização da alteridade e revela seu lado mais descarnado. Em "Minha Irmã Elba", da espanhola Cristina Fernández Cubas, a infância reaparece através de uma investigação da crueldade, a solidão e a perda. Como no conto de Enríquez, trata-se de uma história de iniciação interrompida, que coloca a infância não como promessa de futuro, mas como queda, obturação, perda de toda futuridade possível. Algo análogo acontece em "Alfredito", da boliviana residente nos Estados Unidos Liliana Colanzi, no qual uma menina se enfrenta à morte de um amigo. Os contos questionam a inocência da infância e exploram a morte das crianças 
como obsessão, modo de transgredir a teleologia reprodutiva e questionar o paradigma heteronormativo nela implicada. ${ }^{2}$ Como já afirmou o teórico Christopher Fynsk, a morte da criança presentifica a quebra de um tabu, evento traumático, dor no estado mais puro, maior ponto de vulnerabilidade humana, cena primária do que Jacques Lacan chama relação psíquica com o "real" e por tanto, limite da linguagem, da representação e da própria possibilidade de dizer (2000, p. 50). A morte da criança toma a mesma estrutura que a relação com a alteridade, como exposição ao outro absoluto. Assim é que devemos entender as crianças mortas que aparecem no livro, como um questionamento do heteronormativo e uma exploração do limite da representação.

Um ponto interligado que recorre muitos dos relatos é o prazer por e pela palavra, a paixão por escrever que é, para as mulheres escritoras, um modo de sobreviver e de lutar. "A escrita é a tecnologia dos cyborgs," afirma Donna Haraway,

a política dos cyborgs é a luta pela linguagem e a luta contra a comunicação perfeita, contra o código único que traduz todos os sentidos perfeitamente, o dogma central do falogocentrismo. É por isso que a política

2 Lee Edelman analisa a infância como símbolo de uma teleologia reprodutiva e da fixidez da heteronormatividade (2004). Por seu lado, Kathryn Bond Stockton entende a infância como questionamento da reprodutividade heterossexual, relacionada a uma sexualidade polimorfa, que quebra com o futuro heteronormativo (2009). 
cyborg insiste no ruído e advoga pela poluição, celebrando a fusão ilegítima entre máquina e animal. (1991, p. 176)

A palavra é um espaço de aliança entre mulheres, uma palavra imperfeita, heterogênea, híbrida, que questiona o dogmático, o único e o falogocéntrico. Em "A densidade das palavras", a argentina Luisa Valenzuela narra com humor a transgressão do papel de submissão feminino recriando um conto de fadas no qual a protagonista desrespeita os imperativos femininos e se dedica ao trabalho com a palavra. ${ }^{3}$ Anos mais tarde, se reúne com sua irmã, quem tinha acatado as imposições de gênero, e forma com ela um coro polifônico. A união entre mulheres que transgrede os imperativos patriarcais também aparece em "Uma mulher notável" da também argentina Angélica Gorodischer, no qual a protagonista simula sua morte com ajuda da sua madrinha para fugir do marido violento. A sororidade e a aliança entre as mulheres se funda na e pela palavra, uma palavra coloquial, fluída, em processo, que percorre todos os contos do volume. Os textos questionam o monolítico e favorecem a diversidade, a fusão com a alteridade.

Insólitas cria linguagens múltiplas destinadas a públicos heterogêneos e irreduzíveis a uma leitura homogênea

3 Para uma análise das questões de gênero nos contos de fadas, que demonstra a multiplicidade de papéis de gênero que neles aparecem, ver o livro Viajando pelo mundo encantado do Era uma vez: configurações identitárias de gênero nos contos de fadas, de Regina Michelli (2020). 
ou monolítica, que abrem espaços, criam desvios para pensar em termos descentrados. Em todos eles o insólito permite "um questionamento da ordem simbólica a partir da transgressão, seja das linguagens ou das convenções culturais, e esse exercício de subversão contra o normativo resulta perturbador e revolucionário" (LÓPEZ PELLISA; RUIZ GARZÓN, 2019, p. 8). As editoras destacam o potencial crítico revolucionário do gênero quando afirmam:

O insólito desmascara a natureza relativa e arbitrária do sistema social, se opõe à ordem institucional e expressa impulsos que deveriam ser reprimidos desde a perspectiva do normativo, pelo qual pode resultar lógico que as mulheres, como identidades que não têm gozado do privilégio, encontrem um espaço de liberdade na narrativa não realista e sua capacidade para apontar para as tensões entre a ideologia e o sujeito humano. (LÓPEZ PELLISA; RUIZ GARZÓN, 2019, p. 9)

As mulheres e seu lugar de enunciação estariam vinculados ao insólito pelo questionamento do normativo, o assinalamento do oculto, do escuro que fica apagado, unidas pela necessidade de encontrar espaços de liberdade diante da arbitrariedade da ordem institucional e das convenções impostas. Haveria uma certa liberdade para as mulheres na narrativa não realista, liberação não exclusivamente individual, mas também coletiva e social. 
Em entrevista, Enríquez, reflete sobre a capacidade crítica do insólito e sua vigência no atual contexto de pandemia pelo Covid-19: "Pensar que a ficção científica e o terror não têm capacidade de crítica é não ter uma leitura estendida" (BATALLA, 2020). A seguir, adiciona: "[o insólito] é um gênero que ajuda a pensar em futuros possíveis, em alternativas possíveis de vida, a questionar como vivemos" (2020). Em documentário recente sobre sua trajetória e obra, Ursula K. Le Guin, uma das autoras fundadoras do gênero, também assinalou sua potencialidade crítica:

Tive que repensar minha aproximação à ficção científica....era importante pensar no privilégio, no poder, na dominação, em termos de gênero, que era algo que a ficção científica e a fantasia não tinham feito [...] O que mudou foi meu ponto de vista. De repente, estamos vendo Terramar... do ponto de vista daqueles que não possuem poder. (CURRY, 2019)

Nos sentidos assinalados por Enríquez e Le Guin, Insólitas descentra os espaços de poder hegemônicos, os cânones estabelecidos, e inclusive a aproximação ao fantástico. Neste livro as mulheres hispânicas repensam o insólito e o tornam um espaço produtivo para pensar, a contrapelo, o privilégio, o poder e a dominação, em termos de gênero, mas também de língua, de idade e de habilidade. ${ }^{4} \mathrm{O}$ insólito Ihes permite

4 Sobre este tema, recomenda-se ver a coletânea organizada por Ana Cristina Dos Santos e 
pensar e narrar desde a perspectiva dos despossuídos, aqueles alheios ao poder, e por isso a aliança entre escritoras e o questionamento fundador de Ocampo diante das convenções literárias e das expectativas do campo continua a resultar tão central.

\section{REFERÊNCIAS}

BATALLA, Juan. Mariana Enríquez: 'Pensar que la ciencia ficción y el terror no tienen capacidad de crítica es quizá no tener una lectura extendida'. Infobae, 22 de julho de 2020. Disponível Em: https://www. infobae.com/cultura/2020/07/22/mariana-enriquez-pensar-la-cienciaficcion-y-el-terror-no-tienen-capacidad-de-critica-es-quiza-no-teneruna-lectura-extendida/. Acesso em 29 mar. 2021.

CURRY, Arwen, Worlds Of Ursula K. Le Guin, 2019. Disponível em: https:// vimeo.com/ondemand/worldsofursulakleguin/376182633. Acesso em 29 de mar. 2021.

EDELMAN, Lee, No Future. Queer Theory and the Death Drive. Durham: Duke University Press, 2004.

FYNSK, Christopher, Infant Figures. The Death of the Infans and Other Scenes of Origins. Stanford, Stanford University Press, 2000.

LÓPEZ-PELLISA, Teresa; LUIS GARZÓN, Ricard. Insólitas: Narradoras de lo fantástico em Latino-américa y España. Madrid: Páginas de Espuma, 2019.

MICHELLI, Regina. Viajando pelo mundo encantado do Era uma vez: configurações identitárias de gênero nos contos de fadas. Rio de Janeiro: Dialogarts, 2020. Disponível em: http://www.dialogarts.ueri.br/admin/ arquivos tfc literatura/ViajandoPeloMundoEncantadoEraUmaVez ff.pdf. Acesso em 14 mar 2021.

SANTOS, Ana Cristina dos; ALAVARCE, Camila da Silva (Orgs.). Vozes insólitas. Representação de diversidades e minorias na literatura e no

Camila da Silva Alavarce intitulada Vozes Insólitas. Representações de diversidades e minorias na literatura e no cinema contemporâneo (2020). 
cinema contemporâneo. Rio de Janeiro: Dialogarts, 2020. Disponível em: http://www.dialogarts.uerj.br/admin/arquivos tfc literatura/vozes insolitas.pdf. Accesso em 14 mar. 2021.

SEGATO, Laura Rita. La escritura en el cuerpo de las mujeres asesinadas en Ciudad Juárez. Buenos Aires: Tinta Limón, 2013.

STOCKTON, Kathryn. The Queer Child, Or Growing Sideways in the Twentieth Century. Durham: Duke University Press, 2009.

ULLA, Noemí, Encuentros con Silvina Ocampo, Buenos Aires, Leviatán, 2003.

\section{Alejandra Judith Josiowicz}

Fez pós-doutorado no Centro de Pesquisa e Documentação de História Contemporânea do Brasil (FGV-CPDOC) com bolsa PNPD-Capes.

É Professora Adjunta no Departamentos de Letras Neolatinas (LNEO) do Instituto de Letras (ILE) da Universidade Estadual de Rio de Janeiro (UERJ).

Participa de grupos de pesquisa sobre infância e literatura infantil, incluindo a Rede de Estudos de História das Infâncias (REHIAL), e do Núcleo de Estudos em Literatura Infantojuvenil da UERJ - NELIJ-UERJ.

Email: alejandra.josiowicz@gmail.com

Lattes: http://lattes.cnpq.br/5755463684001653

ORCID iD: https://orcid.org/0000-0002-3525-1833

Página: https://sites.google.com/view/alejandra-josiowicz/home 